\title{
Symptomatic knee osteoarthritis treatment using autologous adipose derived stem cells and platelet-rich plasma: a clinical study
}

\author{
Khanh Hong-Thien Bui ${ }^{1}$,Triet Dinh Duong ${ }^{1}$, Nhan Thanh Nguyen ${ }^{1}$,Thanh Duc Nguyen ${ }^{1}$,Vien Tuong Le ${ }^{1}$, Viet Thanh Mai ${ }^{1}$, Nhan \\ Lu-Chinh Phan', Dung Minh Le', Ngoc Kim Ngoc'2, Phuc Van Pham ${ }^{2, *}$
}

\author{
${ }^{1}$ University of Medical Center, Ho Chi Minh University of Medicine and Pharmacy, Ho Chi Minh City, Vietnam; ${ }^{2}$ Laboratory of Stem Cell Re- \\ search and Application, University of Science, Vietnam National University, Ho Chi Minh City, Vietnam. * Corresponding author: \\ pvphuc@hcmuns.edu.vn
}

Received: 15 December 2013 / Accepted: 02 February 2014 / Published online: 7 February 2014

(C) The Author(s) 2014. This article is published with open access by BioMedPress (BMP), Laboratory of Stem Cell Research and Application.

\begin{abstract}
Osteoarthritis is one of the most common diseases, and it affects $12 \%$ of the population around the world. Although the disease is chronic, it significantly reduces the patient's quality of life. At present, stem cell therapy is considered to be an efficient approach for treating this condition. Mesenchymal stem cells (MSCs) show the most potential for stem cell therapy of osteoarthritis. In fact, MSCs can differentiate into certain mesodermal tissues such as cartilage and bone. Therefore, in the present study, we applied adipose tissue-derived MSCs to osteoarthritis treatment. This study aimed to evaluate the clinical efficiency of autologous adipose tissue-derived MSC transplantation in patients with confirmed osteoarthritis at grade II and III. Adipose tissue was isolated from the belly, and used for extraction of the stromal vascular fraction (SVF). The SVF was mixed with activated platelet-rich plasma before injection. The clinical efficiencies were evaluated by the pain score (VAS), Lysholm score, and MRI findings. We performed the procedure in 21 cases from 2012 to 2013 . All 21 patients showed improved joint function after 8.5 months. The pain score decreased from 7.6 \pm 0.5 before injection to $3.5 \pm 0.7$ at 3 months and $1.5 \pm 0.5$ at 6 months after injection. The Lysholm score increased from $61 \pm 11$ before injection to $82 \pm 8.1$ after injection. Significant improvements were noted in MRI findings, with increased thickness of the cartilage layer. Moreover, there were no side-effects or complications related to microorganism infection, graft rejection, or tumorigenesis. These results provide a new opportunity for osteoarthritis treatment. Level of evidence: IV.
\end{abstract}

Keywords - Osteoarthritis, Adipose tissue-derived stem cell, Stromal vascular fraction, Platelet-rich plasma.

\section{INTRODUCTION}

Cartilage injury is a common clinical condition, especially in people aged over 40 years. Such injuries can lead to osteoarthritis if they are not suitably treated. Osteoarthritis is a chronic degenerative progression that results in cartilage degeneration, osteophytes, reorganization of side-bone, and loss of joint function (Wieland et al., 2005). At the present time, cartilage injuries are treated with drugs (Dougados, 2001; Eyigor et al., 2006) or injection with hyaluronic acid (Chen et al., 2011; Karatosun et al., 2008; Spakova et al., 2012) to reduce symptoms and pain, and control inflammation. However, these therapies have limited efficiency and fail to prevent disease progression (Schroeppel et al., 2011).
Cultured chondrocyte transplantation has also been used to treat cartilage injury since 1994. Autologous chondrocytes are isolated and expanded before injection into the joint. Cultured chondrocyte transplantation has provided some good outcomes (Frisbie et al., 2008; Kreuz et al., 2013; Lee et al., 2003). However, this method also has some limitations, especially the lack of cultured chondrocyte sources, as almost all cultured chondrocytes die after long-term culture because of maturation.

A recent study showed the presence of stem cells in adipose tissue, and termed these cells adipose-derived stem cells

Symptomatic knee osteoarthritis treatment using autologous adipose derived stem cells 
(ADSCs). These cells are considered to be mesenchymal stem cells (MSCs) that exhibit some particular properties. They are able to adhere to the flask surface with a fibroblastlike shape, and successfully differentiate into osteoblasts, chondrocytes, and adipocytes (Zuk et al., 2001). They also express particular markers of MSCs, such as CD44, CD73, CD90, and CD105, but are negative for CD14, CD34, and CD45 (Gaiba et al., 2012; Khan et al., 2012; Zhu et al., 2012; Zimmerlin et al., 2013). This profile is similar to the profile of MSCs described by Dominici and colleagues (Dominici et al., 2006). Compared with MSCs from bone marrow and umbilical cord blood, ADSCs have many advantages (Christodoulou et al., 2013). In particular, ADSCs represent a suitable autologous cell source. To date, ADSCs have become excellent candidates for research and clinical applications. Many studies have shown that ADSC transplantation efficiently improved almost all symptoms of certain diseases, such as liver fibrosis (Harn et al., 2012), nerve defects (Gu et al., 2012; Liu et al., 2011; Santiago et al., 2009), ischemia (Mazo et al., 2012; Rigol et al., 2010), skeletal muscle injury (Pecanha et al., 2012), passive chronic immune thrombocytopenia (Xiao et al., 2012), and myocardial infarction (Yang et al., 2012) in animals, and systemic sclerosis in humans (Riordan et al., 2009; Scuderi et al., 2013).

Given the huge potential of ADSCs, many studies have been conducted over the last few years, including preclinical trials and clinical trials carried out to treat cartilage injury and osteoarthritis. Some of the animal models used were dogs (Black et al., 2008; Black et al., 2007; Guercio et al., 2012), rabbits (Toghraie et al., 2011), horses (Frisbie et al., 2009), rats (Lee and Im, 2012), mice (ter Huurne et al., 2012; Van Pham et al., 2013b), and goats (Murphy et al., 2003).

In another study, however, ADSCs were considered to inhibit cartilage regeneration. This conclusion was drawn from experiments of ADSC transplantation in rats. The study showed that ADSCs highly expressed and secreted VEGF-A into the culture supernatant. The supernatant was found to inhibit chondrocyte proliferation, reduce Sox9, alcan, and collagen II mRNA levels, reduce proteoglycan synthesis, and increase apoptosis. Histological examination revealed that defects with ADSCs had no tissue ingrowth from the edges of the defect (Lee et al., 2012).

In previously published studies, we evaluated the in vitro and animal model (mice) effects of platelet-rich plasma (PRP) on ADSC differentiation into chondrocytes. In vitro, we showed that PRP treatment of ADSCs promoted their differentiation and proliferation into chondrogenic cells (Van Pham et al., 2013a). These cells strongly expressed collagen II, Sox9, and aggrecan. As a result, PRP-pretreated ADSCs improved healing of injured articular cartilage in a mouse model compared with untreated ADSCs. In another study, we investigated the effects of PRP on non-expanded stromal vascular fraction (SVF) transplantation in a cartilage injury mouse model, and observed great regeneration of cartilage (Van Pham et al., 2013b). Moreover, there were no non-beneficial effects from ADSC or SVF transplantation recorded in the animal models (Van Pham et al., 2013a).

Based on these results, we performed this clinical trial with the aim of evaluating the efficiency and side-effects of nonexpanded SVF transplantation in combination with PRP in osteoarthritis grade II and III.

\section{MATERIALS - METHODS}

\section{Inclusion criteria}

All patients enrolled in this study were required to sign the consent form. All procedures used in the study were approved by the Ethical Committee of the University Medical Center, Ho Chi Minh University of Medicine and Pharmacy (Ho Chi Minh City, Vietnam).

Regarding inclusion criteria, all patients were aged above 18 years, had osteoarthritis from cartilage injury at grade II to III, had failed in drug treatment as well as autologous cartilage transplantation, had a Lysholm score lower than 65, were committed with a surgical condition, and were HIVnegative.

A total of 21 patients were enrolled in the study. The study was designed with the endpoint classification of safety and efficacy, the intervention model was single group assignment without a control, the masking was open label, and the primary purpose was treatment.

\section{Isolation of SVF from adipose tissue}

The SVF was isolated from the abdominal adipose tissue of each patient. For this, approximately $50-100 \mathrm{ml}$ of lipoaspirate was collected from each patient into two $50-\mathrm{ml}$ sterile syringes. All procedures and manipulations were approved the Hospital Ethical Committee (Ho Chi Minh City Medicine and Pharmacy University Hospital, Ho Chi Minh City, Vietnam). The syringes were stored in a sterile box at $2-8^{\circ} \mathrm{C}$ and immediately transferred to the laboratory. The SVF was isolated using an ADSC Extraction Kit (GeneWorld, Ho Chi Minh City, Vietnam) according to the manufacturer's instructions. This kit was approved by the Vietnam Ministry of Health as a medical device. Briefly, $50-100 \mathrm{ml}$ of lipoaspirate was placed in a sterile disposable $250-\mathrm{ml}$ conical centrifuge tube (Corning, Tewksbury, MA) and washed twice with sterile PBS by centrifugation at $400 \times g$ for $5 \mathrm{~min}$ at room temperature. Next, the adipose tissue was digested using SuperExtract Solution containing collagenase at $37^{\circ} \mathrm{C}$ for $30 \mathrm{~min}$ with agitation at 5-min intervals. The suspension was centrifuged at $800 \times g$ for $10 \mathrm{~min}$, and the SVF was obtained as the pellet. The pellet was washed twice with PBS to remove any residual enzyme, and resuspended in PBS for determination of

Symptomatic knee osteoarthritis treatment using autologous adipose derived stem cells 
the cell quantity and viability using an automatic cell counter (NucleoCounter; Chemometec, Denmark).

\section{Activated PRP preparation}

Activated PRP was derived from the peripheral blood of the same patient as the adipose tissue using a New-PRP Pro Kit (GeneWorld) according to the manufacturer's guidelines. Briefly, $20 \mathrm{ml}$ of peripheral blood was collected into vacuum tubes and centrifuged at $800 \times g$ for $10 \mathrm{~min}$. The plasma fraction was collected and centrifuged at $1000 \times g$ for $5 \mathrm{~min}$ to obtain a platelet pellet. Most of the plasma was then removed, leaving $3 \mathrm{ml}$ of plasma for resuspension of the platelets. This preparation was inactivated PRP. Finally, PRP was activated using activating tubes containing $100 \mu \mathrm{l}$ of $20 \%$ $\mathrm{CaCl}_{2}$.

\section{Preparation of product for transplantation}

The product for injection was a mixture of the obtained SVF and activated PRP. Activated PRP was used to dilute the SVF to achieve a suitable dose for injection.

\section{Injection of product and monitoring}

All patients were examined and evaluated according to the inclusion criteria at 2 weeks before the transplantation. All patients were re-evaluated at 1,3 , and 6 months posttransplantation. The primary outcome measurements included the Lysholm score, change from baseline in quality of life score, and number of adverse events reported (after 1, 3, and 6 months). The secondary outcome measurements were changes from baseline in X-rays of the affected joint (MRI score) (after 6 months).

All patients were examined after collection of aspirated adipose tissue and peripheral blood to obtain the SVF and activated PRP. The patients waited in the surgery room for $2 \mathrm{~h}$ before receiving the injected mixture of SVF and PRP without joint surgery.

\section{RESULTS}

This study started in early 2012 and finished in early 2013. All patients examined had osteoarthritis at grade II to III. The results showed that were significant improvements in joint function after 8.5 months. The pain score (VAS Walking Index) changed significantly and gradually decreased from $7.6 \pm 0.5$ before injection to $3.5 \pm 0.7$ after 3 months and $1.5 \pm 0.5$ after 6 months. The Lysholm score also improved significantly and gradually increased from $61 \pm 11$ before injection to $71 \pm 13$ after 3 months and $82 \pm 8.1$ after 6 months.
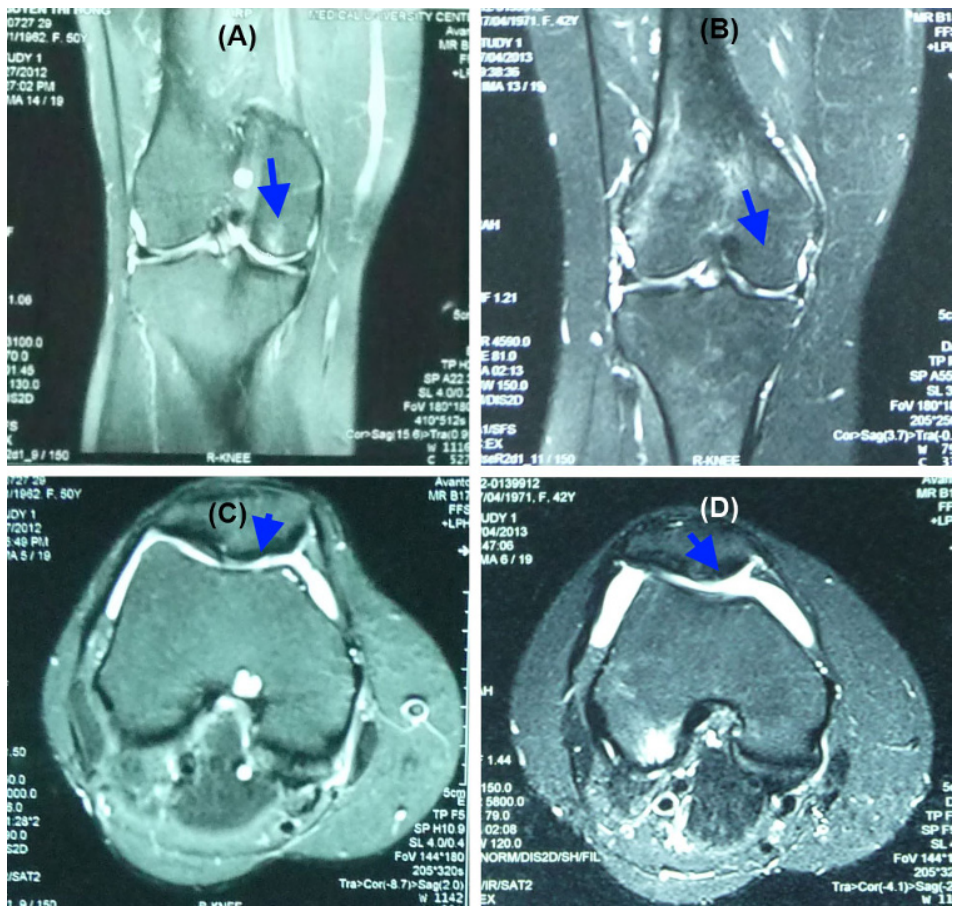

Figure 1. MRI analysis of a joint before and after SVF and PRP injection. At 6 months after injection, MRI signals showed that there were some improvements in the injured cartilage and regeneration of the injured cartilage sites (B) compared with the pretreatment condition (A). The cartilage layer was also thicker (D) compared with the pretreatment condition (C). 
Regarding the histology, MRI analysis showed that the cartilage layers were partly regenerated at the injured sites. The MRI pictures showed that the cartilage layer was also thicker after 6 months of treatment.

Overall, $100 \%$ of patients were pleased with the treatment results. They felt that their pain levels gradually reduced, especially after 3 months. There were 15 patients $(71.24 \%)$ who could go up and down stairs after 3 months. Currently, $100 \%$ of patients can move normally and carry out normal living activities. More importantly, $100 \%$ of patients had no side-effects or complications related to the procedure, such as microorganism infection or tumor formation at the joint.

\section{DISCUSSION}

Knee osteoarthritis is a common chronic orthopedic disease that significantly reduces the patient's quality of life. In recent years, stem cell application to osteoarthritis has rapidly developed, with promising results in preclinical and clinical trials. This clinical study showed that SVF and PRP injection brought about some good outcomes for patients with osteoarthritis.

One of the clear results regarding the effects of the SVF and PRP injection was that the patients could feel pain reduction. In fact, the VAS score was significantly decreased after 6 months (from $7.6 \pm 0.5$ to $1.5 \pm 0.5$ ). Pain reduction is related to the role of PRP. At the present time, PRP is widely used for certain clinical conditions, especially in the management of pain and inflammation. PRP was reported to inhibit the $\mathrm{NF} \kappa \mathrm{B}$ cascade, by preventing the induction of $\mathrm{NF} \kappa \mathrm{B}$ from $\mathrm{I} \kappa \mathrm{B} \alpha$, thereby trapping NF $\kappa \mathrm{B}$ in the cytoplasm and preventing the induction of $\mathrm{NF} \kappa \mathrm{B}$ target genes (van Buul et al., 2011). In a previous study, it was shown that NFKB was activated by IL- $1 \beta$ in chondrocytes obtained from osteoarthritis patients. Once $N F \kappa B$ is activated, almost all gene-related anabolic pathways, such as type II collagen and aggrecan synthesis, are blocked. However, PRP treatment can rescue these pathways (van Buul et al., 2011; Wu et al., 2011).

The anti-inflammatory and pain reduction effects are also related to growth factor components in PRP. PRP contains a pool of cytokines, including HGF, PDGF, IGF, TGF- $\beta$, EGF, and FGF (Amable et al., 2013; Banfi, 2012; Hamilton et al., 2013). HGF was proven to act as an enhancer of NFkB inhibitor (Bendinelli et al., 2010), decrease the production of the cytokine IL-6, and increase the anti-inflammatory cytokine IL-10 (Coudriet et al., 2010). TGF- $\beta 1$ abolishes CXCR4 expression in monocytes (Bendinelli et al., 2010; Coudriet et al., 2010). IGF-1 and PDGF also inhibit activation of NFkB (Montaseri et al., 2011).

The anti-inflammatory and pain reduction effects are also partly contributed by soluble factors secreted from the SVF or ADSCs. ADSCs secrete many important soluble factors, such as HGF, VEGF, NGF, EGF, FGF, and TGF- $\beta$ (Kilroy et al., 2007; Salgado et al., 2010; Van Pham et al., 2013a). Unlike PRP, growth factors from ADSCs are continuously produced after injection of these cells into the joint.

The second effect of SVF and PRP injection was stimulation of cartilage growth at the injected sites. The results showed that the cartilage layer gradually became thicker at 3 and 6 months after injection, and that some injured cartilage sites in particular were regenerated. These findings arise from the combined effects of ADSCs and PRP. In some of our previous studies in mouse models, we recorded that SVF and PRP as well as ADSC and PRP stimulated neocartilage formation (Van Pham et al., 2013a; Van Pham et al., 2013b). As ADSCs highly express VEGF-A, which inhibits the growth of cartilage, transplantation of ADSCs alone can inhibit cartilage growth (Lee et al., 2012). In this research and a previous study in a mouse model (Van Pham et al., 2013a), we used ADSCs in combination with activated PRP to inhibit VEGF production, thereby improving ADSC differentiation into chondrocytes.

The existence of grafted ADSCs at injected sites as well as the participation of ADSCs in neocartilage formation were not verified in this study. However, in another study (data not shown), we labeled human ADSCs with GFP and injected them into the joints of NOD/SCID model mice. At 30 days after transplantation, GFP-labeled cells at the knee cartilage were collected and evaluated for the expression of certain genes related to chondrocytes, such as collagen type II, aggrecan, and Sox9. The results showed that GFP-labeled cells strongly expressed these genes. These findings showed that ADSCs in the knee joint microenvironment were induced to differentiate into chondrocytes.

The beneficial effects of ADSC transplantation have also been recorded in clinical trials in certain countries. In a recent study, Jo et al. (2014) performed a clinical study involving treatment of knee osteoarthritis by injection of ADSCs in 18 patients. After 6 months, patients injected with $1 \times 10^{8}$ cells had significantly improved WOMAC score and size of cartilage defect, with no adverse events (Jo et al., 2014).

In a study involving fewer patients, Pak (2011) reported that almost all patients showed significant improvements in all clinical outcomes at the final follow-up examination. All clinical results were significantly improved at the 2-year follow-up compared with the 12-month follow-up (Pak, 2011).

\section{Conclusion}

To summarize, autologous SVF injection in combination with PRP is a safe and efficient method for treating osteoarthritis of grade II and III. The efficiency of transplantation clearly improved after 6 months. Overall, 100\% of patients

Symptomatic knee osteoarthritis treatment using autologous adipose derived stem cells 
were pleased with this method. Pain was strongly reduced after 3 months, the cartilage layers were thicker after 6 months, and the quality of life was significantly improved. Although further studies with control subjects and more patients need to be performed to confirm the above results, this study suggests that our treatment is a promising minimally invasive therapy for osteoarthritis patients.

\section{ACKNOWLEDGMENT}

This work was funded by grants from GeneWorld Ltd. SHTP, HCM, VN.

\section{Abbreviations}

MSCs: Mesenchymal stem cells; SVF: Stromal vascular fraction; ADSC: Adipose derived stem cell; VEGF: Vascular endothelial growth factor; PRP: Platelet rich plasma; PBS: Phosphate buffered saline; TGF- $\beta$ : transforming growth factor-beta; EGF: epidermal growth factor; bFGF: basic fibroblast growth factor.

\section{Competing interests}

The authors declare that they have no competing interests.

\section{Authors' contributions}

All authors read and approved the final manuscript. KHTB, TDD, NTN, TDN, VTL, VTM carried out the clinical surgery, included adipose aspirate, SVF and PRP injection. NLCP, DML isolated SVF and PRP preparation. NKP participated in designing the study. PVP prepared the manuscript in cooperation with all other authors.

\section{Open Access}

This article is distributed under the terms of the Creative Commons Attribution License (CC-BY 4.0) which permits any use, distribution, and reproduction in any medium, provided the original author(s) and the source are credited.

\section{References}

Amable, P.R., Carias, R.B., Teixeira, M.V., da Cruz Pacheco, I., Correa do Amaral, R.J., Granjeiro, J.M., and Borojevic, R. (2013). Plateletrich plasma preparation for regenerative medicine: optimization and quantification of cytokines and growth factors. Stem cell research \& therapy $4,67$.

Banfi, G. (2012). Platelet rich plasma. Journal of biological regulators and homeostatic agents 26, 1 .

Bendinelli, P., Matteucci, E., Dogliotti, G., Corsi, M.M., Banfi, G., Maroni, P., and Desiderio, M.A. (2010). Molecular basis of antiinflammatory action of platelet-rich plasma on human chondrocytes: mechanisms of NF-kappaB inhibition via HGF. Journal of cellular physiology 225, 757-766.

Black, L.L., Gaynor, J., Adams, C., Dhupa, S., Sams, A.E., Taylor, R., Harman, S., Gingerich, D.A., and Harman, R. (2008). Effect of intraarticular injection of autologous adipose-derived mesenchymal stem and regenerative cells on clinical signs of chronic osteoarthritis of the elbow joint in dogs. Veterinary therapeutics : research in applied veterinary medicine 9, 192-200.

Black, L.L., Gaynor, J., Gahring, D., Adams, C., Aron, D., Harman, S., Gingerich, D.A., and Harman, R. (2007). Effect of adiposederived mesenchymal stem and regenerative cells on lameness in dogs with chronic osteoarthritis of the coxofemoral joints: a randomized, double-blinded, multicenter, controlled trial. Veterinary therapeutics : research in applied veterinary medicine 8 , 272-284.

Chen, L., Ling, P.X., Jin, Y., and Zhang, T.M. (2011). Hyaluronic acid in combination with chondroitin sulfate and hyaluronic acid improved the degeneration of synovium and cartilage equally in rabbits with osteoarthritis. Drug discoveries \& therapeutics 5, 190194.

Christodoulou, I., Kolisis, F.N., Papaevangeliou, D., and Zoumpourlis, V. (2013). Comparative Evaluation of Human Mesenchymal Stem Cells of Fetal (Wharton's Jelly) and Adult (Adipose Tissue) Origin during Prolonged In Vitro Expansion: Considerations for Cytotherapy. Stem cells international 2013, 246134.

Coudriet, G.M., He, J., Trucco, M., Mars, W.M., and Piganelli, J.D. (2010). Hepatocyte growth factor modulates interleukin-6 production in bone marrow derived macrophages: implications for inflammatory mediated diseases. PloS one 5, e15384.

Dominici, M., Le Blanc, K., Mueller, I., Slaper-Cortenbach, I., Marini, F., Krause, D., Deans, R., Keating, A., Prockop, D., and Horwitz, E. (2006). Minimal criteria for defining multipotent mesenchymal stromal cells. The International Society for Cellular Therapy position statement. Cytotherapy 8, 315-317.

Dougados, M. (2001). The role of anti-inflammatory drugs in the treatment of osteoarthritis: a European viewpoint. Clinical and experimental rheumatology 19, S9-14.

Eyigor, S., Hepguler, S., Sezak, M., Oztop, F., and Capaci, K. (2006). Effects of intra-articular hyaluronic acid and corticosteroid therapies on articular cartilage in experimental severe osteoarthritis. Clinical and experimental rheumatology 24, 724 .

Frisbie, D.D., Bowman, S.M., Colhoun, H.A., DiCarlo, E.F., Kawcak, C.E., and McIlwraith, C.W. (2008). Evaluation of autologous chondrocyte transplantation via a collagen membrane in equine articular defects: results at 12 and 18 months. Osteoarthritis and cartilage / OARS, Osteoarthritis Research Society 16, 667-679.

Frisbie, D.D., Kisiday, J.D., Kawcak, C.E., Werpy, N.M., and McIlwraith, C.W. (2009). Evaluation of adipose-derived stromal vascular fraction or bone marrow-derived mesenchymal stem cells for treatment of osteoarthritis. Journal of orthopaedic research : official publication of the Orthopaedic Research Society 27, 16751680.

Gaiba, S., Franca, L.P., Franca, J.P., and Ferreira, L.M. (2012). Characterization of human adipose-derived stem cells. Acta cirurgica brasileira / Sociedade Brasileira para Desenvolvimento Pesquisa em Cirurgia 27, 471-476.

Gu, J.H., Ji, Y.H., Dhong, E.S., Kim, D.H., and Yoon, E.S. (2012). Transplantation of adipose derived stem cells for peripheral nerve 
regeneration in sciatic nerve defects of the rat. Current stem cell research \& therapy 7, 347-355.

Guercio, A., Di Marco, P., Casella, S., Cannella, V., Russotto, L., Purpari, G., Di Bella, S., and Piccione, G. (2012). Production of canine mesenchymal stem cells from adipose tissue and their application in dogs with chronic osteoarthritis of the humeroradial joints. Cell biology international 36, 189-194.

Hamilton, B., Tol, J.L., Knez, W., and Chalabi, H. (2013). Exercise and the platelet activator calcium chloride both influence the growth factor content of platelet-rich plasma (PRP): overlooked biochemical factors that could influence PRP treatment. British journal of sports medicine.

Harn, H.J., Lin, S.Z., Hung, S.H., Subeq, Y.M., Li, Y.S., Syu, W.S., Ding, D.C., Lee, R.P., Hsieh, D.K., Lin, P.C., et al. (2012). Adiposederived stem cells can abrogate chemical-induced liver fibrosis and facilitate recovery of liver function. Cell transplantation 21, 27532764.

Jo, C.H., Lee, Y.G., Shin, W.H., Kim, H., Chai, J.W., Jeong, E.C., Kim, J.E., Shim, H., Shin, J.S., Shin, I.S., et al. (2014). Intra-articular injection of mesenchymal stem cells for the treatment of osteoarthritis of the knee: A proof-of-concept clinical trial. Stem cells (Dayton, Ohio).

Karatosun, V., Unver, B., Ozden, A., Ozay, Z., and Gunal, I. (2008). Intra-articular hyaluronic acid compared to exercise therapy in osteoarthritis of the ankle. A prospective randomized trial with long-term follow-up. Clinical and experimental rheumatology 26, 288-294.

Khan, W.S., Adesida, A.B., Tew, S.R., Longo, U.G., and Hardingham, T.E. (2012). Fat pad-derived mesenchymal stem cells as a potential source for cell-based adipose tissue repair strategies. Cell proliferation 45, 111-120.

Kilroy, G.E., Foster, S.J., Wu, X., Ruiz, J., Sherwood, S., Heifetz, A., Ludlow, J.W., Stricker, D.M., Potiny, S., Green, P., et al. (2007). Cytokine profile of human adipose-derived stem cells: expression of angiogenic, hematopoietic, and pro-inflammatory factors. Journal of cellular physiology 212, 702-709.

Kreuz, P.C., Gentili, C., Samans, B., Martinelli, D., Kruger, J.P., Mittelmeier, W., Endres, M., Cancedda, R., and Kaps, C. (2013). Scaffold-assisted cartilage tissue engineering using infant chondrocytes from human hip cartilage. Osteoarthritis and cartilage / OARS, Osteoarthritis Research Society 21, 1997-2005.

Lee, C.R., Grodzinsky, A.J., Hsu, H.P., and Spector, M. (2003). Effects of a cultured autologous chondrocyte-seeded type II collagen scaffold on the healing of a chondral defect in a canine model. Journal of orthopaedic research : official publication of the Orthopaedic Research Society 21, 272-281.

Lee, C.S., Burnsed, O.A., Raghuram, V., Kalisvaart, J., Boyan, B.D., and Schwartz, Z. (2012). Adipose stem cells can secrete angiogenic factors that inhibit hyaline cartilage regeneration. Stem cell research \& therapy 3,35 .

Lee, J.M., and Im, G.I. (2012). SOX trio-co-transduced adipose stem cells in fibrin gel to enhance cartilage repair and delay the progression of osteoarthritis in the rat. Biomaterials 33, 2016-2024.

Liu, G.B., Cheng, Y.X., Feng, Y.K., Pang, C.J., Li, Q., Wang, Y., Jia, H., and Tong, X.J. (2011). Adipose-derived stem cells promote peripheral nerve repair. Archives of medical science : AMS 7, 592596.

Mazo, M., Hernandez, S., Gavira, J.J., Abizanda, G., Arana, M.,
Lopez-Martinez, T., Moreno, C., Merino, J., Martino-Rodriguez, A., Uixeira, A., et al. (2012). Treatment of reperfused ischemia with adipose-derived stem cells in a preclinical Swine model of myocardial infarction. Cell transplantation 21, 2723-2733.

Montaseri, A., Busch, F., Mobasheri, A., Buhrmann, C., Aldinger, C., Rad, J.S., and Shakibaei, M. (2011). IGF-1 and PDGF-bb suppress IL1beta-induced cartilage degradation through down-regulation of NF-kappaB signaling: involvement of Src/PI-3K/AKT pathway. PloS one 6 , e28663.

Murphy, J.M., Fink, D.J., Hunziker, E.B., and Barry, F.P. (2003). Stem cell therapy in a caprine model of osteoarthritis. Arthritis and rheumatism 48, 3464-3474.

Pak, J. (2011). Regeneration of human bones in hip osteonecrosis and human cartilage in knee osteoarthritis with autologous adiposetissue-derived stem cells: a case series. Journal of medical case reports 5, 296

Pecanha, R., Bagno, L.L., Ribeiro, M.B., Robottom Ferreira, A.B., Moraes, M.O., Zapata-Sudo, G., Kasai-Brunswick, T.H., Campos-deCarvalho, A.C., Goldenberg, R.C., and Saar Werneck-de-Castro, J.P. (2012). Adipose-derived stem-cell treatment of skeletal muscle injury. The Journal of bone and joint surgery American volume 94, 609-617.

Rigol, M., Solanes, N., Farre, J., Roura, S., Roque, M., Berruezo, A., Bellera, N., Novensa, L., Tamborero, D., Prat-Vidal, C., et al. (2010). Effects of adipose tissue-derived stem cell therapy after myocardial infarction: impact of the route of administration. Journal of cardiac failure 16, 357-366.

Riordan, N.H., Ichim, T.E., Min, W.P., Wang, H., Solano, F., Lara, F., Alfaro, M., Rodriguez, J.P., Harman, R.J., Patel, A.N., et al. (2009). Non-expanded adipose stromal vascular fraction cell therapy for multiple sclerosis. Journal of translational medicine 7, 29.

Salgado, A.J., Reis, R.L., Sousa, N.J., and Gimble, J.M. (2010). Adipose tissue derived stem cells secretome: soluble factors and their roles in regenerative medicine. Current stem cell research \& therapy 5, 103-110.

Santiago, L.Y., Clavijo-Alvarez, J., Brayfield, C., Rubin, J.P., and Marra, K.G. (2009). Delivery of adipose-derived precursor cells for peripheral nerve repair. Cell transplantation 18, 145-158.

Schroeppel, J.P., Crist, J.D., Anderson, H.C., and Wang, J. (2011). Molecular regulation of articular chondrocyte function and its significance in osteoarthritis. Histology and histopathology 26, 377394.

Scuderi, N., Ceccarelli, S., Onesti, M.G., Fioramonti, P., Guidi, C., Romano, F., Frati, L., Angeloni, A., and Marchese, C. (2013). Human adipose-derived stromal cells for cell-based therapies in the treatment of systemic sclerosis. Cell transplantation 22, 779-795.

Spakova, T., Rosocha, J., Lacko, M., Harvanova, D., and Gharaibeh, A. (2012). Treatment of Knee Joint Osteoarthritis with Autologous Platelet-Rich Plasma in Comparison with Hyaluronic Acid. American journal of physical medicine \& rehabilitation / Association of Academic Physiatrists.

ter Huurne, M., Schelbergen, R., Blattes, R., Blom, A., de Munter, W., Grevers, L.C., Jeanson, J., Noel, D., Casteilla, L., Jorgensen, C., et al. (2012). Antiinflammatory and chondroprotective effects of intraarticular injection of adipose-derived stem cells in experimental osteoarthritis. Arthritis and rheumatism 64, 3604-3613.

Toghraie, F.S., Chenari, N., Gholipour, M.A., Faghih, Z., Torabinejad, S., Dehghani, S., and Ghaderi, A. (2011). Treatment of 
osteoarthritis with infrapatellar fat pad derived mesenchymal stem cells in Rabbit. The Knee 18, 71-75.

van Buul, G.M., Koevoet, W.L., Kops, N., Bos, P.K., Verhaar, J.A., Weinans, H., Bernsen, M.R., and van Osch, G.J. (2011). Platelet-rich plasma releasate inhibits inflammatory processes in osteoarthritic chondrocytes. The American journal of sports medicine 39, 23622370 .

Van Pham, P., Bui, K.H., Ngo, D.Q., Vu, N.B., Truong, N.H., Phan, N.L., Le, D.M., Duong, T.D., Nguyen, T.D., Le, V.T., et al. (2013a). Activated platelet-rich plasma improves adipose-derived stem cell transplantation efficiency in injured articular cartilage. Stem cell research \& therapy $4,91$.

Van Pham, P., Hong-Thien Bui, K., Quoc Ngo, D., Tan Khuat, L., and Kim Phan, N. (2013b). Transplantation of Nonexpanded Adipose Stromal Vascular Fraction and Platelet-Rich Plasma for Articular Cartilage Injury Treatment in Mice Model. Journal of Medical Engineering 2013, 7.

Wieland, H.A., Michaelis, M., Kirschbaum, B.J., and Rudolphi, K.A. (2005). Osteoarthritis - an untreatable disease? Nature reviews Drug discovery 4, 331-344.

Wu, C.C., Chen, W.H., Zao, B., Lai, P.L., Lin, T.C., Lo, H.Y., Shieh, Y.H., Wu, C.H., and Deng, W.P. (2011). Regenerative potentials of platelet-rich plasma enhanced by collagen in retrieving proinflammatory cytokine-inhibited chondrogenesis. Biomaterials 32, 5847-5854.

Xiao, J., Zhang, C., Zhang, Y., Zhang, X., Zhao, J., Liang, J., Zhong, X., and Chen, Y. (2012). Transplantation of adipose-derived mesenchymal stem cells into a murine model of passive chronic immune thrombocytopenia. Transfusion 52, 2551-2558.

Yang, J.J., Yang, X., Liu, Z.Q., Hu, S.Y., Du, Z.Y., Feng, L.L., Liu, J.F., and Chen, Y.D. (2012). Transplantation of adipose tissue-derived stem cells overexpressing heme oxygenase-1 improves functions and remodeling of infarcted myocardium in rabbits. The Tohoku journal of experimental medicine 226, 231-241.

Zhu, X., Du, J., and Liu, G. (2012). The comparison of multilineage differentiation of bone marrow and adipose-derived mesenchymal stem cells. Clinical laboratory 58, 897-903.

Zimmerlin, L., Donnenberg, V.S., Rubin, J.P., and Donnenberg, A.D. (2013). Mesenchymal markers on human adipose stem/progenitor cells. Cytometry Part A : the journal of the International Society for Analytical Cytology 83, 134-140.

Zuk, P.A., Zhu, M., Mizuno, H., Huang, J., Futrell, J.W., Katz, A.J., Benhaim, P., Lorenz, H.P., and Hedrick, M.H. (2001). Multilineage cells from human adipose tissue: implications for cell-based therapies. Tissue engineering 7, 211-228.

\section{Cite this article as:}

Bui, K., Duong, T., Nguyen, N., Nguyen, T., Le, V., Mai, V., Phan, N., Le, D., Phan, N., \& Pham, P. (2014). Symptomatic knee osteoarthritis treatment using autologous adipose derived stem cells and plateletrich plasma: a clinical study. Biomedical Research And Therapy, 1(1):2-8. 